\title{
Mobilities into (and out of) Konomerume (Donderskamp)
}

\author{
Racquel-María Yamada
}

\section{1 \\ Introduction $^{1}$}

This chapter explores mobility, language practices, and identity among residents of Konomerume, ${ }^{2}$ a predominantly Kari'nja ${ }^{3}$ community, ethnically, on the banks of the Wajambo River in Suriname. I examine mobilities among

1 I would like to acknowledge the kindness and professional courtesy extended to me by the editors and other authors of this volume. Their patient reading and thoughtful suggestions have improved this work immeasurably. I would also like to express my deep gratitude to members of the Konomerume community with whom I have had the amazing privilege of working for so many years. I take full responsibility for any errors, omissions, or oversights.

2 Residents' auto-designation for the community is Konomerume. Outsiders, including the Surinamese government, refer to the community as Donderskamp. I use community members' designation throughout. There is a bit of a "chicken or egg" question regarding the name of the community. Most outsiders' accounts attribute the name Donderskamp to a Dutch missionary, Father Peter Donders, who worked in Suriname in the late 18oos. Elders in the community, however, claim the name Konomerume predates Donders. It should be noted that Dutch donder and Kari'nja konomerume both translate to 'thunder.'

3 The term Karinja is the auto-designation of people who are either speakers of the language or who self-identify as ethnically Kari'nja. This particular spelling also reflects the practical orthography developed in Konomerume. Community members and I have developed a practical orthography that represents more phonetic detail than other orthographies. For example, a regular process of palatalisation following /i/ is represented with digraphs with a second element, /j/, indicating a palatalised consonant (see Hoff 1968: 43 for a detailed discussion of palatalisation in Kari'nja). In some cases, as in §6.2.1 example (5), a prefixed /i-/ palatalises the following consonant and then elides. The practical orthography represents the word as it is pronounced. In addition, the $/ \mathrm{r} /$ spelling represents the Aretyry dialect-in Tyrewuju, the name is pronounced [kali?nja]. The language name has been spelled in various ways depending on the particular orthography employed. Different spellings include Cariña, Kari'na, Kali'na, Kalihna, and Kalinya, among others. The language is known variously as Carib, Carib of Suriname, Galibi, and Maraworno. A language name or spelling that is more common in one region or context may be less common in another. I employ Konomerume community members' spelling and designation throughout. C.f. $§ 6$ for further detail on dialects.

(C) RACQUEL-MARÍA YAMADA, 2015 | DOI 10.1163/9789004280120_007

This is an open access chapter distributed under the terms of the Creative Commons Attribution-

Noncommercial 3.o Unported (CC-BY-NC 3.0) License. 
migrants to Konomerume and describe reasons for and types of movement. In addition, I describe differences among migrant groups in terms of language practice (who speaks which language to whom and why (c.f. Fishman 1991)), language attitudes (including attitudes toward different Kari'nja dialects), integration (the extent to which migrants participate in the community at large), and identity (especially as it relates to language revitalisation). I adopt here Fishman's (2010) conceptualisation of identity and its relationship to both language and ethnicity as highly contextualised and dependent on "circumstances and contrasts that play upon it, modify it, and create or recreate it (2010: xxviii)." As such, I explore migrants' language practices, attitudes, integration, and identity from both insider and outsider perspectives.

Finally, a discussion of implications for the identification of dialect areas is included. This chapter represents a small-scale look at mobilities within an individual community and how they relate to language practices, identity, and attitudes. In addition, I discuss the implications of migration, attitudes, and contact linguistics on the identification of dialect boundaries and posit a subdialect area based on initial sociolinguistic findings.

In part 1, I describe Konomerume in terms of location and demographics. This is followed by some background information on the project itself and how data were gathered in parts 2 and 3 . Part 4 begins with a description of types of mobility as they relate to the Konomerume situation. I then assess particular groups of in-migrants to Konomerume, including their motivations for migration, language practices and attitudes, and their level of integration into the community. I organise the individual groups in progression from least well- to most well-integrated. Part 5 examines tensions between speakers of the two Kari'nja dialects spoken in Suriname: Aretyry and Tyrewuju. This is followed by a brief description of the Aretyry documentation, preservation, and revitalisation program in Konomerume. In part 6, I explore social and linguistic indicators of dialect boundaries and use these factors to posit a potential subdialect area. Finally, part 7 provides conclusions and a description of directions for future research projects in Konomerume and elsewhere.

2

\section{Demographics}

Konomerume is located in the Sipaliwini District of Suriname, on the banks of the Wajambo River. The Wajambo River flows in a roughly east-west direction, meeting the Coppename River to the east, and the Nickerie River to the west. The Nickerie River provides access to the Corantijn River, ${ }^{4}$ which forms the

4 This is the Surinamese spelling for this river name. 


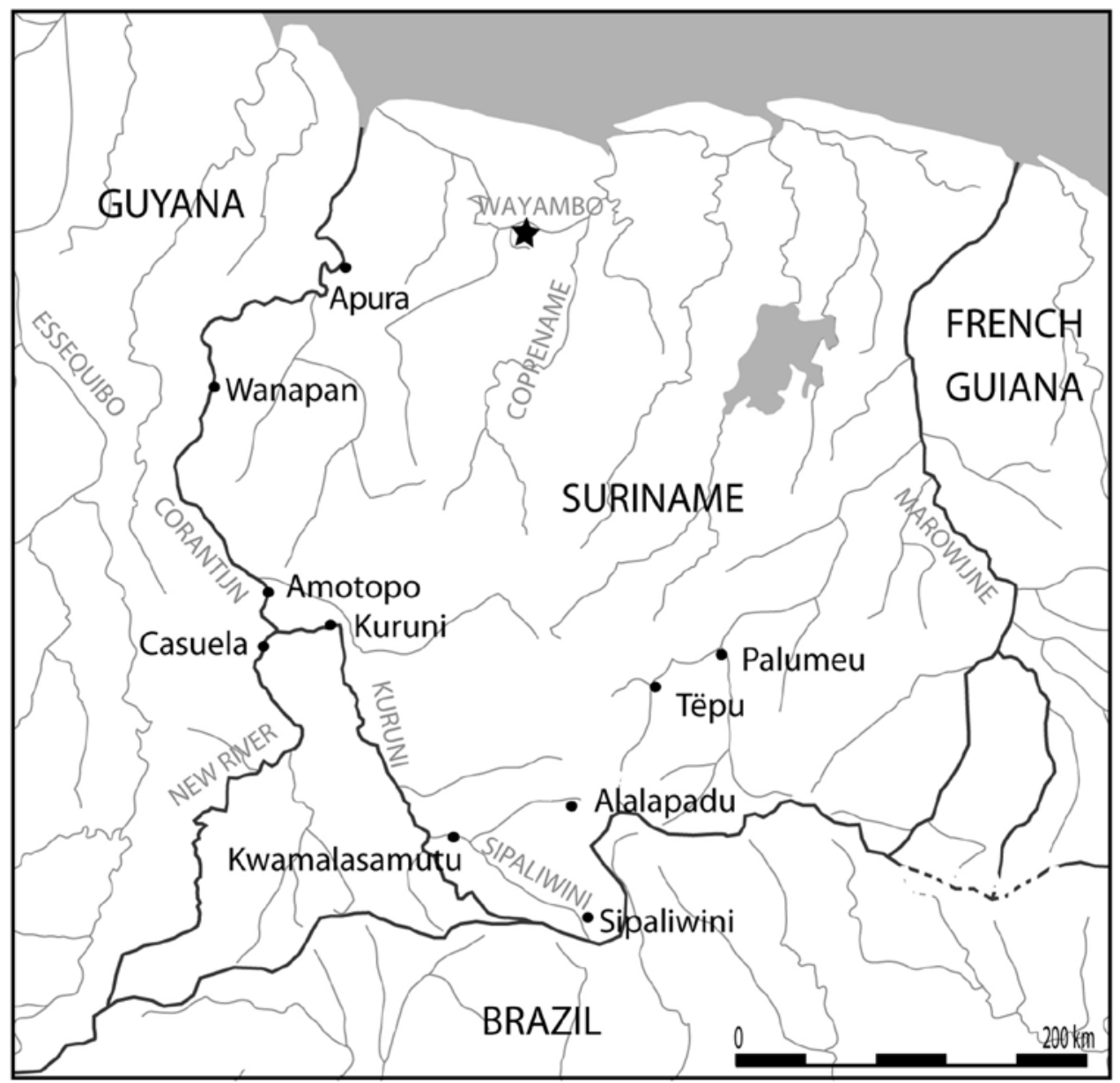

FIGURE 6.1 Map of Suriname.

border between Suriname and Guyana. In Figure 6.1, the approximate location of Konomerume is indicated with a black star.

According to 2004 census data (Suriname General Bureau of Statistics Census Office), the community is comprised of approximately 349 residents (including in-migrants), most of whom self-identify as ethnically Kari'nja, with a small percentage self-identifying as ethnically Lokono or Warao. ${ }^{5}$ The

5 Kari'nja, Lokono, and Warao are names for both languages and ethnicities. It is common for someone who is not fluent in either language to say, "I am Lokono and Warao." The conflation between language and ethnicity has led to occasional tension between speakers and nonspeakers with more than one accusation such as, "How can you call yourself Lokono when you don't even speak the language?" A full examination of what constitutes identity in these 
languages Kari'nja (Cariban) and Lokono (Arawakan) are both highly endangered. Warao (isolate) is no longer spoken in Suriname. The primary language of communication in Konomerume is Sranantongo, a so-called English-lexified Creole language that also functions as Suriname's lingua franca. Dutch, the official language, is learned as a second language in the community elementary school. For those who have learned Dutch, there is a wide range of fluency. Elementary school teachers, community leaders, and those who travel regularly to Paramaribo have a greater command of the language than members of the community at large.

Konomerume represents a geographic and social border between Kari'nja and Lokono in the Coppename/Wajambo region of Suriname. Konomerume was originally composed of two villages - one Lokono and one Kari'nja. Intermarriage eventually led to the merger of the two communities. The nearest community to the west, Tapuripa, is primarily Lokono, and that to the east, Cornelis Kondre, is primarily Kari'nja. Most Konomerume residents who claim Lokono heritage are not fluent in the language, though approximately 3-4 middle-aged adults are fluent native speakers who only occasionally use the language. Residents who are ethnically Warao, all migrants from Guyana, do not speak the Warao language at all. Of the two indigenous languages spoken in Konomerume, Kari'nja is dominant and has both more speakers and more non-speakers who self-identify as ethnically Kari'nja.

The Kari'nja language has been identified as highly endangered (UnEsco 2003) with approximately 7,430 speakers worldwide (Lewis 2009). In addition to Suriname, Kari'nja is spoken in French Guiana, Guyana, and Venezuela. Two dialects have been identified in Suriname, Tyrewuju and Aretyry. Aretyry, spoken in the central and western regions of the country, is the nonprestige variety. Of the 1,200 Kari'nja speakers in Suriname (Carlin 2001), the vast majority speaks the prestige dialect, Tyrewuju.

In Konomerume, four groups of Kari'nja speakers are roughly delimited along age lines. Elder native speakers, aged 65 and above, still use Kari'nja daily as the primary language of communication amongst themselves. Middleaged speakers, who are approximately 40 to 65 years old, are native speakers who no longer use the language daily. They primarily use Kari'nja with their elder parents, and Sranantongo or Dutch amongst themselves and with their

cases is outside the scope of the present paper, but note that this is not uncommon elsewhere. Here in Oklahoma, I often hear, "I am Kiowa and Choctaw," from people who speak neither. In general, I use the language names to refer to both language and group members' self-defined ethnic identity. 
children. Younger adults, aged 20 to 40 , are "understanders." Most understand the language but do not speak it. Currently, children are not learning the language natively, but there is an effort to revive the language through formal lessons in the community elementary school, and expanded contexts of use. These facts place the community at Stage 7 of Fishman's (1991: 87-111) Graded Intergenerational Disruption Scale (GIDS). Since elders still speak the language with each other, middle-aged adults speak Kari'nja with elder parents, young adults understand but don't speak the language, and very few children are addressed in the language, the gap between speakers exists between the middle-aged and young adult generations.

Data for this chapter were gathered primarily through open-ended ethnographic life-story interviews conducted jointly by myself and the former Konomerume village chief. My interviews were conducted in Sranantongo, and the chief conducted his in Kari'nja. Our work for this project fulfilled multiple purposes in the community. In addition to providing data on migration and language attitudes in Konomerume, recorded interviews represent part of the documentary corpus of Kari'nja. Further, interviews with community elders provided place names and descriptions of the boundaries of traditional hunting, fishing, and gathering areas. This information continues to be used as part of a greater effort to establish land rights for members of indigenous communities in Suriname. Interview data were supplemented with census figures from the 2004 census.

Since 2005, I have been working with members of the Konomerume community on documentation, description, preservation, and revitalisation of the Aretyry dialect of Kari'nja. Based on the Community Partnerships Model of social science field research (Yamada 2010), our work is collaborative and inclusive. Community member partners and I share the workload for any project we undertake together. For this project, community members conducted interviews and operated recording equipment, and have used text data in support of other projects.

Originally, I had planned to compare Kari'nja migration patterns across political and dialect borders. However, a dearth of cases made this untenable. None of the speakers interviewed in Konomerume knew of any cases of Kari'nja migrants to Guyana or Venezuela, and community members and I were able to identify only two individuals who had migrated to Tyrewuju-speaking 
communities. One had met her future husband while attending intermediate school in Paramaribo and then migrated to his home community of Galibi, Suriname. The other moved to Maná, in French Guiana, for similar reasons.

I then decided to interview the largest group of migrants to Konomerume, those from the Guyanese community of Orealla, on the Suriname/Guyana border. However, interviews revealed patterns that applied to other migrants to the community. Furthermore, there were both similarities and differences in language practices, attitudes, and identity based on community of origin. Thus, I broadened focus to include mobilities among all migrants to Konomerume in terms of reasons and types of movement, differences in language practices, acceptance by community members with more established histories in Konomerume, and identity among different groups.

Types of Mobility

A goal for this project was to examine migration into Konomerume as it relates to language practice (who speaks which language to whom and why) and the extent to which migrants are integrated and accepted into the community. Indicators of community integration and acceptance are qualitative rather than quantitative. Evaluation of integration is based on self-reports, observed participation in community socio-cultural events, and the holding of leadership or decision-making positions in the community. Level of acceptance by other community members is based on self-reports and ethnographic interviews with community elders.

Texts of life story interviews revealed three primary types of mobility, each of which differs in terms of language practices, the migrants' own identity, and their acceptance and integration within the community. Furthermore, each mobility type differs in terms of traditional migration parameters of space, time, motivation, and socio-cultural factors (Lewis 1982; Boyle et al. 1998). As defined by the United Nations Development Programme (UNDP 2010), migrants to Konomerume include guest workers, return migrants, and those with existing family ties in the community at the time of migration. Each of these is described in the sections that follow.

\subsection{Guest Workers}

Members of two different guest worker groups have settled in Konomerume. The first and most recent group is also the smallest. These are workers employed by the local lumber mill, Bromet Lumber. Located approximately an hour from Konomerume by dugout canoe, Brometville hosts guest labourers from Brazil as well as supervisors from other parts of Suriname. The Brazilian labourers 
are typically temporary migrants who have come to Suriname for economic reasons. All are young adult males and many are supporting families back in Brazil. Most intend to return there. They often travel to Konomerume for recreation on the weekends and occasionally develop relationships with young women in the community. However, even those who have taken partners in the community are solidly outsiders. Few acquire more than the most elementary Sranantongo, and none are fluent in Dutch, Kari'nja, or Lokono. They commute between the community and the lumber mill and usually only come home to their partners in Konomerume on the weekends. Their partners speak to them in Sranantongo with some code switching to Dutch. They respond in rudimentary Sranantongo. These young men communicate with each other in Brazilian Portuguese and occasionally teach a few words of Portuguese to their partners. Although they attend weekend social events, they are viewed more as guests than as active participants. They rarely contribute to food or drink gathering and preparation, do not participate in cultural rituals, and rarely interact with community leaders or elders. They do not hold positions of leadership in the community and are not invited to community meetings. Their overall impact on language attitudes and practices in the community is minimal. ${ }^{6}$

In addition to Brazilian labourers, Bromet Lumber employs supervisors from other areas of Suriname (typically, from Paramaribo). Housed at Brometville, supervisors are longer-term residents than labourers. Most have completely relocated to Brometville, though some maintain second residences in Paramaribo. Two different supervisors from Brometville have taken partners in Konomerume. They are better integrated in the community than the temporary Brazilian labourers and are fluent in Dutch and Sranantongo. Neither claims indigenous heritage, but their status as Surinamese affords them a greater degree of acceptance in the community. One encourages his wife and in-laws to speak Kari'nja with his mixed-ethnicity children, and his wife has been actively involved with Kari'nja revitalisation. Although he lives at Brometville during the workweek, he has built a house in Konomerume where his wife and children reside (and to which he returns on weekends and holidays). He is a long-term resident of the community and supports community development by providing scrap lumber for community projects, running a small store, and hosting cultural events.

6 Members of this group do have some economic impact on the community during the time they are in Suriname in that they occasionally contribute to individual families' household expenses. However, there have been no identified cases of them having an impact on migration in that none has taken a partner back to Brazil. When they leave, they leave as they arrived: alone. 
The second group of guest workers to arrive in Konomerume includes those who came from Guyana beginning in the 196os. At the time, a project to build the southern East-West Highway from Apoera to Paramaribo drew guest labourers from Guyana who both worked to build the road as well as on barges transporting sand and/or lumber via the Nickerie, Wajambo, and Coppename rivers to Paramaribo. They arrived in the country as guest workers and then took partners from and settled in Konomerume. Few have returned to Guyana since settling in Suriname. All of these migrants came to Suriname from Orealla, Guyana, an Amerindian community that lies across the border from Apoera along the Corantijn River. Some are originally from other parts of Guyana, but all came through Orealla as an intermediate stop.

Primarily of Warao or Lokono heritage, members of this group do not speak an indigenous language. All members of this group are middle-aged adults, an age group that has retained Kari'nja in Konomerume. Since none of the Guyanese migrants speak an indigenous heritage language, indigenous language attrition likely happened earlier in parts of Guyana than in Suriname. All are native English speakers who acquired Sranantongo while working in Suriname. They speak Sranantongo with their families and amongst themselves, with some occasional code switching to English. Members of this group self-identify as outsiders, but most are well integrated in terms of participation in socio-cultural events. Although some hold formal positions of leadership in the community, other community members nonetheless identify them as outsiders. Their status as outsiders is evidenced by in-group descriptions of their social missteps. Drinking alcohol during social and cultural events is common and occasional drunkenness is generally accepted. However, if someone of Warao heritage behaves badly after drinking alcohol, it is not uncommon to hear, "Oh, you know how they are," as though Warao are more likely than Kari'nja to engage in inappropriate behaviour while drunk.

\subsection{Return Migrants}

Members of the young adult generation, return migrants include those who moved to Paramaribo for educational or economic opportunities and then returned to Konomerume. There is a K-6 elementary school in Konomerume, but students who are successful and want to continue their formal schooling must relocate to Paramaribo. This places a tremendous burden on families who must find safe, affordable housing in the capital as well as pay school fees. Living far from their immediate families in an unfamiliar environment, children who move to Paramaribo for school struggle to succeed. Families are often unable to shoulder the financial burden of supporting a child in the capital and many of them return to Konomerume after one or two years. 
Some youth who are unable to continue their schooling leave school and find jobs in Paramaribo. Commonly, young men have gone to work for "the shrimp boats," usually foreign-owned industrial trawl fisheries (FAO 2006). They spend months at sea (FAO 2000a), often working around the clock (FAO 200ob). Most young men who do this work are unable to sustain it for more than a couple of years, and many return to Konomerume.

Return migrants include youth who moved to Paramaribo to continue their formal schooling and were unable to continue for financial or other reasons. Members of this group may or may not have spent a period of time working in Paramaribo prior to returning to Konomerume. Some members of this group relocated to Paramaribo for financial reasons, taking menial jobs there, but found town life more challenging than life in Konomerume. Return migrants are native Sranantongo speakers who acquired Dutch at school. Many understand Kari'nja, but none speaks it natively. Since the revitalisation movement that has been underway in Konomerume for the past five years, many members of the return migrant group have been working to reclaim Kari'nja. They have led the push to include Kari'nja in the elementary school curriculum, and they form the bulk of young adult learners in the Kari'nja classes described in \$5.2. As return migrants, they are well accepted and well integrated into the community. They have positive attitudes toward multilingualism, and are working to revitalise Kari'nja. Most speak Sranantongo amongst themselves and Dutch, Sranantongo, and some Kari'nja with their children.

\subsection{Family Reunification}

Although this group overlaps somewhat with the return migrant group, there are decided differences between the two groups in terms of age and motivation. Family reunification migrants are all members of the middle-aged and elder generations, and many were raised in other communities before migrating to Konomerume. As such, they did not "return" to their immediate families as return migrants have, rather they relocated to Konomerume in order to be nearer to extended family members. In some cases, these migrants are elders who have migrated to Konomerume to be nearer to their adult children (as opposed to return migrants who are children returning to their parents). Some have spent time living in Paramaribo before migrating to Konomerume. This group has proved the most interesting in terms of what it reveals about social correlates of linguistic dialect borders.

Members of this group come from several communities in Suriname including Cornelis Kondre, Tibiti, Goede Hoop, Pikin Saron, and Bigi Poika. All came to Konomerume because of family ties. Some came to visit extended family members and stayed; others came with the intention of relocating. Those 
from Tibiti relocated to Konomerume in the late 1980 s when the civil war in Suriname (DeVries, 2005) caused their community to disband.

Migrants to Konomerume who came because of family ties are all Kari'nja speakers, and all took partners who were either Kari'nja or of mixed Kari'nja/ Lokono heritage. They have strongly positive attitudes toward Kari'nja and continue to speak the language amongst themselves and to their adult children. All have also acquired Sranantongo and some are marginally fluent in Dutch. The communities from which they migrated are similar to Konomerume in terms of ethnic and linguistic background of community members (all come from other Kari'nja communities to the east of Konomerume), level of Kari'nja endangerment in the community, and availability of formal schooling.

Interviews with members of this group revealed that they form two subgroups based on geographic region of origin. Members of the two subgroups originate from either the Konomerume region or outside of the Konomerume region. Migrants who come from communities along the Wajambo and Coppename rivers (Cornelis Kondre, Tibiti, and Goede Hoop) form the "inregion" group, and those from communities along the Saramacca river (Bigi Poika, Pikin Saron) form the "out-region" group.

There is a lot of fluidity throughout the space that makes up the in-region group of communities. There are strong family ties from one community to another. Members of this subgroup in Konomerume are solidly insiders who hold positions of influence and power. They are well-respected elders who have a solid sense of place. In most cases, I would not have known they were not originally from Konomerume if I had not asked.

Members of the out-region group are also ethnically Kari'nja who are native speakers of the language. Although they are also well integrated in the community, they self-identify as outsiders, regardless of the length of time they have resided in Konomerume. They rarely vote during community decision-making meetings and will preface contributions to such meetings with comments like, "I am not from here, so I really shouldn't speak, but..." This particular quote came from an out-region group member who had, at that time, lived in the community for over 35 years, married a member of the in-region group, and raised nine children in Konomerume. Other community members' response was to reassure him that he could, by now, be considered an in-region member of the community. However, had he not prefaced his statement in such a selfdeprecating way, it is likely he would have faced grumbles of dissatisfaction such as, "He's not even from here! Why is he speaking up?"

For family reunification migrants, region of origin plays a greater role than expected in integration and acceptance in the community. Kari'nja heritage does not guarantee community acceptance. Coming from the Wajambo/ 
Coppename region seems to be a better predictor of a migrant's potential for full integration into and acceptance by the greater Konomerume community.

As stated in $\S 3$, one of the original motivations for this chapter was the examination of mobility across dialect borders. The dearth of cases made such a study untenable. However, initial data gathering brought to light the issue of dialect tensions between Tyrewuju and Aretyry. It is possible that Kari'nja migrants have not crossed dialect borders because of the deep-seated acrimony between speakers of the two dialects represented in Suriname. In this section, I examine the tension between the two dialects and then describe a movement to revitalise the nonprestige variety.

\subsection{Aretyryversus Tyrewuju}

The deep and multi-faceted tension between the prestige Tyrewuju dialect and non-prestige Aretyry is evident in both outsiders' perceptions and in Aretyry Kari'njas' own intuitions. Both the Surinamese government and foreign nationals who travel to Suriname to conduct research tend to focus their energies on Tyrewuju. Although Aretyry Kari'nja participate in the Association of Indigenous Village Leaders in Suriname (henceforth, the vids), both formal and social positions of leadership and power within the organisation are predominantly maintained by Tyrewuju. The development of a Kari'nja math program for elementary school students (supported by the vIDs) was initially directed primarily at Tyrewuju children. ${ }^{7}$ Additionally, the most commonly used name for the Aretyry dialect, Murato, is considered pejorative by speakers. From "mulatto," meaning 'of mixed African descent,' the term itself indicates that Aretyry is somehow a bastardised version of the more conservative Tyrewuju. ${ }^{8}$ This sense of Aretyry being somehow "less than" is widespread enough that even those who are purportedly linguistically savvy hold this bias. ${ }^{9}$

The negative perceptions held by people in positions of power and influence in Suriname has led to a sort of inner turmoil for Aretyry speakers as well

7 It has since expanded in scope to be more inclusive and is being used in Konomerume.

8 It should be noted that this is an impression not supported by linguistic facts. In fact, Tyrewuju Kari'nja employs more innovative constructions than the more conservative Aretyry.

9 I have had personal interactions with two different university-schooled leaders who expressed a clear bias against Aretyry based solely on impressionistic accounts rather than on actual language data. 
as semi- or non-speakers who self-identify as ethnically Kari'nja from Aretyryspeaking areas. On the one hand, they maintain that they have a right to speak and promote their own dialect of Kari'nja. Many have argued for the legitimacy of their variety of the language, and proudly proclaim themselves Aretyrydifferent from, but not inferior to, Tyrewuju. On the other hand, it is tremendously difficult not to fall victim to outsiders' negative assertions about the dialect. There seems to be, for many Aretyry, an insecurity stemming from a deeply ingrained sense that Tyrewuju is somehow "better" than Aretyry. This is evident in Aretyry speakers' fawning characterisations of Tyrewuju as "deeper" or "more real" than Aretyry. For example, one Aretyry speaker whose daughter moved to Galibi with her Tyrewuju partner once bragged to me that her grandchildren were being raised to speak "flawless, true Kari'nja," as opposed to the presumably flawed version that she, herself, spoke.

Aretyry speakers' reverence toward Tyrewuju as a prestige variety is tempered by a preference for hearing Aretyry. I have heard more than one Aretyry speaker mock Tyrewuju speakers for sounding "like babies." This characterisation is due in part to the [l] [r] alternation between the dialects (Aretyry has [r] where Tyrewuju has [l]). According to some Aretyry speakers, using an [l] where they would use an [r] represents an early stage in Kari'nja acquisition.

Despite Aretyry speakers' insecurity in some cases, there is a strong and overarching pride in "Aretyryness," manifest in the Konomerume revitalisation project described in the next section. Speakers and non-speakers alike were adamant that the variety to be preserved and revitalised in Konomerume be Aretyry. One of the leaders of the revitalisation movement told me that, in his opinion, Tyrewuju have plenty of resources to preserve their own variety of the language, and Aretyry deserves the same amount of focus and attention. "We are not from Galibi," he said. "Why would we want to speak like them?" (F.M., personal communication).

\subsection{Aretyry Revitalisation}

Since 2005, Konomerume community members and I have been working to document, preserve, and revitalise the Aretyry dialect of Kari'nja. My role in revitalisation is that of consultant, trainer, and materials developer. At the request of community members, I have developed and delivered training workshops on principles of Kari'nja linguistics, language teaching methodology, curriculum planning, and materials development. I have also written grants that have provided technological resources for documentation and materials development. Community leaders now have the capacity to accomplish most such tasks on their own.

Interestingly, it is migrants in the Family Reunification and Return Migrant groups who have been both the strongest supporters and the most involved 
participants in revitalisation. They have spearheaded most projects and seen to it that they come to fruition. Perhaps their greater exposure to Tyrewuju and experiences with discrimination while in Paramaribo have led members of these groups to be the strongest asserters of Aretyry identity. They tend to be the most vocal about the legitimacy of the dialect, and have been most willing to work toward its revitalisation. That is not to say that those who have not lived elsewhere and then migrated to Konomerume are unsupportive, but rather that those who have tended to be more proactive in their support are Aretyry in-migrants to Konomerume.

To date, we have developed pedagogical materials that include a multiple-language dictionary, several "Books on Tape" (interlinear glossed texts of spoken Kari'nja with accompanying CD recordings), a one-year introductory, elementary school-level Kari'nja curriculum with teaching activities and materials, and classroom decorations in the language. The village elementary school, overseen by the Roman Catholic church, allows teachers 30 minutes of "flex time" per day. It was decided two years ago that this time would be spent on Kari'nja. Teachers have used this time to pilot the curriculum and make changes, as well as to introduce the Kari'nja math curriculum developed in cooperation with the vids. In addition to the elementary school courses, there are classes available for adults. Taught by fluent native speakers of the middle-aged group, the classes are aimed primarily at young adults who have children enrolled in the elementary school. The goal is for parents and children to support each others' learning. This system was developed in the hope that children and their parents could support each others' Kari'nja learning and motivate a return to intergenerational communication in and transmission of the language (Fishman 1991).

From the outset, speakers were adamant that Aretyry be the variety documented and taught in Konomerume. As young adults have gained more experience and developed fluency in the language, they have become more passionate advocates for their own dialect. The pride of "Aretyryness" has found its way to this younger generation. They are more confident in their status as Aretyry Kari'nja worthy of an identity independent of Tyrewuju, and they are less accepting of negative characterisations of their dialect and identity.

\section{Dialect Variation}

One of the motivations underlying the Aretyry revitalisation movement is the emerging understanding among community members that Aretyry is a conventionalised, rule-governed variety of Kari'nja that is just as worthy of revitalisation as the prestige Tyrewuju. A subgoal of my own research into 
the language is to describe the patterns of Aretyry on their own merit in an attempt to understand the differences and similarities between the two varieties. Furthermore, I hope to continue to validate Aretyry's status as a standard version of Kari'nja proper rather than some sort of bastardised "mulatto."

One important facet of dialect variation is the treatment of borrowings. Aretyry and Tyrewuju treat loanwords slightly differently. An examination of these phenomena serves three primary purposes. First of all, it strengthens our descriptive understanding of the two dialects. Secondly, this knowledge may shed light on earlier migration patterns. Finally, an enriched awareness of the linguistic differences between Aretyry and Tyrewuju may also shed light on previously undescribed variation in the Kari'nja dialect continuum in Suriname and beyond.

Treatment of loanwords is by no means the only point of divergence between the two dialects. One expects to find variation in all linguistic systems: phonological, lexical, semantic, and syntactic. For the present study, borrowing phenomena provide an ideal starting point because they have been well described by Renault-Lescure (2009, Rose and Renault-Lescure 2008, Colomb and Renault-Lescure this volume) for Tyrewuju. Future research will examine additional aspects of variation.

\subsection{Dialect Areas}

Kari'nja communities in the Coppename/Wajambo ("in-region") and Saramacca ("out-region") areas have been described as forming part of the Aretyry dialect area (Courtz 2008; Hoff 1968), which is said to span from just west of Paramaribo to the Guyana border. The Kari'nja-speaking communities to the east of Paramaribo and into French Guiana are said to form the Tyrewuju dialect area. However, community members from the Coppename/Wajambo and Saramacca river regions note differences in their respective speech patterns. Those from Konomerume describe the variety spoken in the Saramacca region as "deeper" and "more Galibi-like" than that spoken in the Coppename/ Wajambo region. Although both are purportedly part of the Aretyry-speaking area, initial sociological observations suggest that there may be a previously unidentified subdialect spoken in the Saramacca region.

Although a full dialect survey is outside the scope of this paper, work for this project revealed an interesting morphosyntactic difference between Aretyry and Tyrewuju Kari'nja. In §6.2, I examine loanword phenomena in Aretyry and Tyrewuju. Renault-Lescure (op. cit.) provides a description of the Tyrewuju system. My own recorded data of Aretyry form the basis for comparison. Future research will examine identified differences between the Aretyry and Tyrewuju 
dialects, such as that described in $§ 6.2$, with a goal of identifying potential differences evidenced between the Kari'nja spoken in the Saramacca river region and that of the Coppename/Wajambo.

This line of inquiry into dialect borders is a direct outcropping of migrationfocused research in Konomerume. That is, had Saramacca region Kari'nja speakers not migrated to Konomerume, speakers' impressions of their different speech patterns may not have come to light. Future research will seek to determine whether differences in loanword phenomena can aid in the description of the variety of Kari'nja spoken in the Saramacca region. Should that variety employ more Tyrewuju-like loanword morphosyntax, it may represent a separate link in the Tyrewuju-Aretyry dialect chain. Interest in identifying this separate sub-dialect began with social evidence (speaker intuitions), and will be described based on linguistic evidence (loanword phenomena, among other structural facts). A possible intermediate dialect between Tyrewuju and Aretyry is the subject of ongoing research and planned future published work.

\subsection{Loanword Phenomena}

Courtz (2008) notes differences in loan words in each of the four identified dialects of Kari'nja. According to Courtz (2008), this is due to different majority languages in each of the countries where Kari'nja is spoken: Spanish in Venezuela, English in Guyana, Dutch and Sranantongo in Suriname, and French in French Guiana. However, in addition to differences in borrowed lexical items, different mechanisms of borrowing may also play a role in distinguishing different dialects.

Code switching between Kari'nja and Sranantongo (and, to a lesser extent, Dutch) is not uncommon. This differs from borrowing in two fundamental ways. Borrowings tend to incorporate smaller units, typically single lexical items, while code switches tend to involve more complex phrase- or clauselevel constructions. In addition, borrowings are more fully adapted to the Kari'nja system phonologically and morphologically. Code switches maintain the phonological shape and morphological inflection of their source. For example, the borrowings in (2) and (3) exhibit a change from Sranantongo [1] to $[\mathrm{r}]$ in Kari'nja. In addition, epenthetic vowels in both examples illustrate Kari'nja (not Sranantongo) phonotactic constraints.

Renault-Lescure (op. cit.) describes morphosyntactic loanword phenomena in the Tyrewuju dialect as spoken along the Suriname/French Guiana border. She identifies four mechanisms of borrowing: noun to noun, objects of postposition poko, suffix -me, and suffix -ma. In the sections that follow, I compare Renault-Lescure's description of the Tyrewuju mechanism to cognates in Aretyry. 
6.2.1 Noun to Noun

According to Renault-Lescure (Rose and Renault-Lescure 2008), nouns are borrowed directly into Kari'nja as nouns, and may then be inflected with Kari'nja nominal morphology. This is illustrated in (1). ${ }^{10}$
(1) zapato (Sp.) > Kari'nja sapato 'shoes'11
perro (Sp.) > Kari'nja pelo 'dog’ (op. cit.:361)

For nouns, the Aretyry dialect has a similar process of borrowing. Nouns in the source language are borrowed as nouns into Kari'nja, regardless of source language. Borrowed terms are subject to Kari'nja phonotactic constraints and are altered to fit the Kari'nja system. Once borrowed, nouns participate fully in Kari'nja nominal constructions and take the full range of person-marking prefixes in conjunction with a suffix that marks a noun as possessed. This is illustrated in examples (2) and (3). In (2), parata, 'money,' is the object of the postposition, poko, 'occupied with,' and in (3) lars, 'boots' is part of a possessed noun phrase construction, 'your boots.'

(2) Parata $^{12}$ poko waty mang.

money about NEG 3.COP

'It's not about money here.' (FM-MA 00580)

(3) a-rarsy-ry ${ }^{13}$

2-rubber.boots-PSSD

'your rubber boots' (MCO2 00225)

\subsubsection{Object of Postposition poko}

Source language verbs are borrowed into Tyrewuju Kari'nja as nouns and are not further derived when so-borrowed. This is illustrated in (4).

10 Examples from Renault-Lescure use the orthography and glosses from their source. All other examples use the practical orthography and glosses developed and used in Konomerume.

11 Abbreviations used in this chapter include: 1: first person, 2: second person, 3: third person, A: A argument, ATTR: attributive, COP: copula, DETR: detransitive, INTNS: intensifier, NEG: negative, NZR: nominaliser, O: O argument, PRED: predicative, PRES: present tense, PRSTNS: present tense, PSSD: possessed, PURP: purpose of motion, RECPST: recent past tense, s: S argument, Sp.: Spanish, VERB: verbaliser, vZR: verbaliser.

12 From Spanish plata 'money'.

13 From Dutch laars 'boots'. 
(4) pentiré $^{14}$ poko man

paint busy.with 3S.COP.PRES

'He is painting.' (Rose and Renault-Lescure 2008: 363 )

The available Aretyry corpus does not include any similar examples of uninflected source language verbs in a poko construction. In one case, a borrowed verb (derived with $-m a$, as described below) is the object of the postposition poko, but it is part of a possessed noun phrase construction. The poko construction may not be a productive borrowing mechanism in Aretyry.

(5) sjetimjary poko...

i-seti ${ }^{15}$-ma-ry $\quad$ poko ${ }^{16}$

3-set-VZR-PSSD occ.with

'(He teaches his son) to set it.' (Lit. 'its setting') (Cassava Demo HeMa 0070)

\subsubsection{Suffix -me}

According to Renault-Lescure (2008), the predicative suffix -me in Tyrewuju is affixed to adjectives or terms that form nouns or verbs through zero derivation in the source language to form nouns in Kari'nja. Renault-Lescure compares the Kari'nja construction illustrated in (6) with the same construction with a borrowing from French, (7).

(6) pitjani-me man

child-PRED 3.COP.PRES

'He is a child.' (Rose and Renault-Lescure 2008: 364 )

(7) pur $^{17}$-me man

pure-PRED 3.COP.PRES

'He is pure.' (Rose and Renault-Lescure 2008: 364)

The cognate construction in Aretyry uses what I analyze as an attributive postposition me, as illustrated in (8). However, this construction represents a marginal case of borrowing and may, in fact, be an example of code switching. The purportedly borrowed terms do not conform to the phonological system in Kari'nja, whereas terms borrowed via other mechanisms typically undergo

\footnotetext{
14 From Guianese Creole verb pentiré 'paint'.

15 From Sranantongo seti 'set'.

16 Cf. note 1 regarding orthographic conventions and phonological processes.

17 From French adjective pur 'pure'.
} 
some sort of phonetic modification to better conform to the Kari'nja system. Although -me represents a common pathway to borrowing in the family, the available Aretyry examples all include non-Kari'nja phonology in the object of the postposition. Example (8) includes a voiceless consonant cluster /st/ not normally found in Kari'nja.

(8) ...bestuur ${ }^{18}$ me we'ijako...

$\begin{array}{llll}\text { bestuur } \quad \text { me } & \text { w-e’i } & \text { jako } \\ \text { leadership ATTR } & \text { 1s-COP } & \text { when } \\ \text { 'When I was in the leadership ...' } & \left(\mathrm{MCO}_{2} \text { 00009) }\right.\end{array}$

6.2.4 Suffix - $m a$

Finally, Renault-Lescure (Rose and Renault-Lescure 2008: 362-364) describes the process for borrowing verbs in the Tyrewuju dialect. The primary mechanism for borrowing verbs into the Tyrewuju dialect is via the verbalising suffix $-m a$. This process is employed to borrow terms in the source language that may be interpreted as either nouns or verbs depending on context (with zero derivation from one word class to the other in the source language). All - $m a$ borrowings to Tyrewuju were ambiguous in the source language and could be interpreted as either nouns or verbs. Tyrewuju Kari'nja borrows the terms as nouns and derives verbs with - $m a$, as illustrated in example (9).

\section{(9) tamusi sibegimae}

tamusi si-begi ${ }^{19}-m a-e$

God 1A-prayer-VERB-PRES

'I pray God.' (Rose and Renault-Lescure 2008: 362)

Initial evidence suggests that a similar borrowing mechanism in the Aretyry dialect works in a more liberal manner. Although a cognate verbalising morpheme - $m a$ also provides a pathway in Aretyry, both nouns and verbs from the source language may be so-borrowed. In the Tyrewuju situation, all of the verbs so derived could be interpreted as either nouns or verbs in the source language. Since the verbaliser - $m a$ in Kari'nja derives verbs from nouns, Renault-Lescure analyses the borrowings as having been borrowed as nouns from the source language and suffixed with Kari'nja - $m a$ to form Kari'nja verbs. While this analysis works for Tyrewuju, it appears that the mechanism operates slightly differently in Aretyry.

18 From Dutch bestuur 'administration'.

19 From Sranantongo begi 'prayer/pray'. 
In the Aretyry dialect, source language nouns and verbs are both suffixed with Kari'nja -ma to form Kari'nja verbs. Although some tokens are of the variety found in Tyrewuju - that is, those where context defines whether they are nouns or verbs in the source language - there are others that cannot be interpreted as belonging to any other word class than verb in the source language. Like example (9) for Tyrewuju, begi in example (10) could be interpreted as either a noun or a verb in Sranantongo. Example (11), too, illustrates a borrowing that is ambiguous in the source language. In these two cases, Aretyry appears to behave exactly as Tyrewuju does.

(10) moro te'ne tamushi shibegimaje jumy.

moro te'ne tamushi si-begi-ma-e jumy

that actually god 1A3O-pray-VZR-PRS.TNS INTNS

'That's why I pray to god a lot.' (UrMaHeAl ooo46)

(11) waijo maro kynishotumanon.

waijo maro kyni-sotu ${ }^{20}-m a-n o n$

salt with 3A3O-salt-VZR-PRs.TNS

'She salts it with salt.' (FF MaAl ooo73)

Although (10) and (11) represent examples that are similar to Tyrewuju, the examples that follow are somewhat different. That is, the borrowed terms in examples (12) to (15) are unambiguously verbs in the source language. The borrowed term in (16) is either a verb or an adjective (zero-derived) in the source language. Verbs are borrowed as verbs into Aretyry Kari'nja and then "Kari'njaised" with the verbalising suffix -ma. Furthermore, borrowings are also subject to phonological and phonotactic constraints of Kari'nja (as can be observed in example (15) with an epenthetic vowel [y] before the suffix - $m a^{21}$ ). The suffix -ma represents a less restricted pathway in Aretyry than that observed in Tyrewuju.

(12) Kynishetimjanon wo'to apoitjo'me.

kyni-seti-ma-non wo'to apoi-to'me

3A3O-set-VZR-PRS.TNS fish catch-PURP

'He sets it in order to catch fish.' (FF MaAl oooo6)

20 From Sranantongo sowtu 'salt/to salt'.

21 Prosody indicates that this is not the nominalising suffix -ry. An affix would have caused a shift in stress not present in this example. 
(13) ... kapyng isharimja'pa na.

kapyng i-sari ${ }^{22}-m a-h p a \quad n a$

NEG 3-satisfy-VZR-NEG 3.COP

'It doesn't satisfy him.' (F F CeAr oo1og)

(14) mose jawo wo'to krimjanon. ${ }^{23}$

mose jawo wo'to krim ${ }^{24}-m a-n o n$

s/he uncle fish clean-vzR-Prs.Tns

'My uncle here cleans fish.' (FF JeNj 0oo33)

(15) sireiffyrymai

si-reifyry ${ }^{25}-m a-i$

1A3O-give-VZR-REC.PST

'I just gave her over.' (FM-MA 00465)

(16) Epinjama'pa mang.

e-pina ${ }^{26}$-ma-hpa mang

DETR-deprive-VZR-NEG 3.COP

'We aren't deprived here.' (FF MaAl ooo34)

Example (11) is an interesting case because in the postpositional phrase waijo maro, the speaker uses the non-borrowed noun waijo 'salt.' However, in the verb phrase, the speaker employs borrowed sowtu, which may be interpreted as either a noun or a verb in Sranantongo. This suggests that in the Aretyry

22 From Sranantongo sari 'to satisfy'.

23 This example illustrates a potentially interesting Sranantongo phenomenon. Sranantongo 'clean,' is pronounced [krin], with an alveolar nasal, elsewhere in Suriname. When Konomerume residents speak Sranantongo, this word is pronounced unambiguously as [krim], with a bilabial nasal. One wonders whether this is a case of the borrower language, Kari'nja, having an effect on the language from which the term was borrowed, Sranantongo. Assimilation to the following verbalising morpheme, -ma, would explain the [krim] pronunciation in Kari'nja. Perhaps this new pronunciation then spread back to the variety of Sranantongo spoken in Konomerume. More than one speaker has noticed variation between Konomerume Sranantongo and that spoken in Paramaribo. Sranantongo variation is certainly beyond the scope of this chapter, but may provide a direction for future research.

24 From Sranantongo krim 'to clean'.

25 From Sranantongo lever 'to give;' originally from Dutch leveren 'to deliver' or uitleveren 'to hand over'.

26 From Sranantongo pina 'poor, to deprive'. 
dialect, verbs from the source language are borrowed as verbs and derived into Kari'nja verbs with -ma. This hypothesis is further supported by examples (13) through (15) which cannot be interpreted as anything other than verbs in the source language.

The Aretyry case may represent an extension of the pathway found in Tyrewuju via analogy. That is, the process that allowed Tyrewuju to borrow nouns from the source language and derive them into Kari'nja verbs was extended to all borrowed verbs in the Aretyry dialect. In the Aretyry dialect, nouns, adjectives, and verbs from the source language are borrowed and derived into Kari'nja verbs with -ma.

Future research will examine loanword phenomena in the Saramacca region in order to confirm speaker intuitions that Saramacca region Kari'nja differs from both Aretyry and Tyrewuju. Additional Aretyry systems will be compared with both Tyrewuju and the Kari'nja spoken in the Saramacca region. In addition to the loanword phenomena described here, prosodic, morphosyntactic, and semantic features of non-verbal predication will be examined. Yamada (2010) describes the Aretyry system, and Alby and Renault-Lescure (2012) describe that employed in Tyrewuju. Future research will compare the two systems with each other as well as with Saramacca river region Kari'nja.

\section{Conclusions}

Homogeneity is often assumed of small indigenous communities (Morrill 2008). Outsiders believe members of small interior communities all think, speak, and react alike and share a single indigenous identity. As the Konomerume case demonstrates, even a small, relatively stable community is not without complexity. People migrate from one community to another for economic and/ or educational reasons and their mobility has effects on members of the host community in terms of language practice, language attitudes, integration, and identity. These effects are in addition to the impact of migration on migrants themselves. In the Konomerume case, residence in Paramaribo prior to settling in Konomerume correlates with an expanded pride in and identification as Aretyry. This is, perhaps, a reaction to discrimination against this nonprestige variety of Kari'nja.

This chapter presents initial case-study evidence in favor of a previously undescribed dialect area. Members of the middle-aged and elder native speaker generations, Family Reunification migrants to Konomerume form two distinct subgroups. In-region migrants from Kari'nja villages along the Wajambo and Coppename rivers are fully integrated and completely accepted 
by other members of the community. Migrants from Kari'nja communities along the Saramacca River form the out-region group. Although they are well integrated and well accepted, they are nonetheless considered outsiders to the community and are subject to particular social rules. They are invited to participate fully in the community with the caveat that they acknowledge their outsider status when participating in community decision-making. Both inregion migrants and established Konomerume residents note that out-region migrants speak a different variety of Aretyry Kari'nja. These social impressions may or may not be borne out by linguistic facts, but will be the subject of future research. This research will begin with an examination of loanword phenomena before progressing to other markers of dialectal difference in an attempt to paint a richer picture of the similarities and differences between all varieties of Kari'nja spoken in Suriname. 